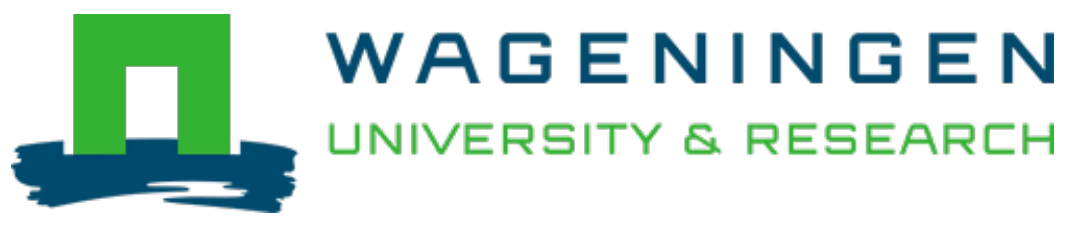

\title{
A guideline to frame stressor effects in freshwater ecosystems
}

Science of the Total Environment

Perujo, N.; Brink, P.J.; Segner, H.; Mantyka-Pringle, C.; Sabater, S. et al

https://doi.org/10.1016/j.scitotenv.2021.146112

This article is made publicly available in the institutional repository of Wageningen University and Research, under the terms of article $25 \mathrm{fa}$ of the Dutch Copyright Act, also known as the Amendment Taverne. This has been done with explicit consent by the author.

Article 25 fa states that the author of a short scientific work funded either wholly or partially by Dutch public funds is entitled to make that work publicly available for no consideration following a reasonable period of time after the work was first published, provided that clear reference is made to the source of the first publication of the work.

This publication is distributed under The Association of Universities in the Netherlands (VSNU) 'Article $25 \mathrm{fa}$

implementation' project. In this project research outputs of researchers employed by Dutch Universities that comply with the legal requirements of Article $25 \mathrm{fa}$ of the Dutch Copyright Act are distributed online and free of cost or other barriers in institutional repositories. Research outputs are distributed six months after their first online publication in the original published version and with proper attribution to the source of the original publication.

You are permitted to download and use the publication for personal purposes. All rights remain with the author(s) and / or copyright owner(s) of this work. Any use of the publication or parts of it other than authorised under article $25 \mathrm{fa}$ of the Dutch Copyright act is prohibited. Wageningen University \& Research and the author(s) of this publication shall not be held responsible or liable for any damages resulting from your (re)use of this publication.

For questions regarding the public availability of this article please contact openscience.library@,wur.nl 


\title{
A guideline to frame stressor effects in freshwater ecosystems
}

\author{
N. Perujo ${ }^{\mathrm{a}, \mathrm{b}, *}$, P.J. Van den Brink ${ }^{\mathrm{c}, \mathrm{d}}$, H. Segner ${ }^{\mathrm{e}}$, C. Mantyka-Pringle ${ }^{\mathrm{f}, \mathrm{g}}$, S. Sabater ${ }^{\mathrm{a}, \mathrm{h}}$, S. Birk ${ }^{\mathrm{i}, \mathrm{j}}$, \\ A. Bruder ${ }^{\mathrm{k}}$, F. Romero ${ }^{1}$, V. Acuña ${ }^{\mathrm{a}, \mathrm{b}}$ \\ a Catalan Institute for Water Research (ICRA), Carrer Emili Grahit 101, 17003 Girona, Spain \\ b University of Girona, Plaça de Sant Domènec 3, 17004 Girona, Spain \\ c Aquatic Ecology and Water Quality Management Group, Wageningen University, P.O. Box 47, 6700 AA, the Netherlands \\ d Wageningen Environmental Research, P.O. Box 47, 6700 AA, the Netherlands \\ e Centre for Fish and Wildlife Health, University of Bern, P.O. Box, 3001, Bern, Switzerland \\ ${ }^{\mathrm{f}}$ Wildlife Conservation Society Canada, Whitehorse, YT, Canada \\ ${ }^{g}$ School of Environment and Sustainability, University of Saskatchewan, Saskatoon, Saskatchewan, Canada \\ ${ }^{\mathrm{h}}$ Institut d'Ecologia Aquàtica (IEA), University of Girona, Campus de Montilivi, 17003 Girona, Spain \\ i University of Duisburg-Essen, Faculty of Biology, Aquatic Ecology, Universitätsstrasse 5, 45141 Essen, Germany \\ ${ }^{j}$ Centre for Water and Environmental Research, University of Duisburg-Essen, Universitätsstrasse 5, 45141 Essen, Germany \\ ${ }^{\mathrm{k}}$ Laboratory of Applied Microbiology, University of Applied Sciences and Arts of Southern Switzerland, Bellinzona, Switzerland \\ ${ }^{1}$ Plant-Soil Interactions, Research Division Agroecology and Environment, Agroscope, Reckenholzstrasse 191, Zurich, Switzerland
}

\section{H I G H L I G H T S}

- Freshwater ecosystems are threatened by pressures and their associated stressors.

- Temporal and spatial profiles are a breakthrough key in the prediction of stressors effects.

- Background environmental levels must be considered to frame stressor effects.

- Framing should be considered in modeling, meta-analyses and in decisionmaking frameworks.

\section{A R T I C L E I N F O}

\section{Article history:}

Received 22 December 2020

Received in revised form 11 February 2021

Accepted 23 February 2021

Available online 1 March 2021

Editor: Ouyang Wei

\section{Keywords:}

Ecotoxicology

River ecology

\section{GRAPHICALA B S T A C T}

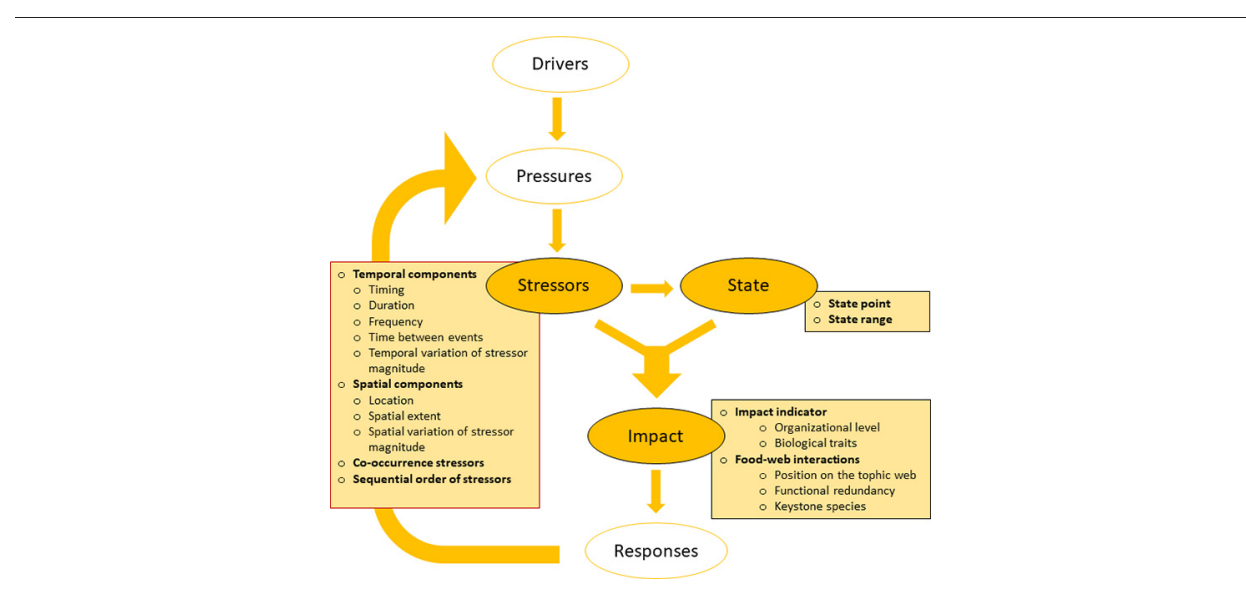

\begin{abstract}
A B S T R A C T
Environmental policies fall short in protecting freshwater ecosystems, which are heavily threatened by human pressures and their associated stressors. One reason is that stressor effects depend on the context in which they occur and it is difficult to extrapolate patterns to predict the effect of stressors without these being contextualized in a general frame. This study aims at improving existing decision-making frameworks such as the DPSIR approach (Driver-Pressure-State-Impact-Response) or ERA (Environmental Risk Assessment) in the context of stressors. Here, we delve into stressor-impact relationships in freshwater ecosystems and develop a guideline which includes key characteristics such as stressor type, stressor duration, location, the natural levels of environmental variables to which each ecosystem is used to, among others. This guideline is intended to be useful in a
\end{abstract}

\footnotetext{
* Corresponding author at: Catalan Institute for Water Research (ICRA), Carrer Emili Grahit 101, Edifici $\mathrm{H}_{2} \mathrm{O}$, Parc Científic i Tecnològic de la Universitat de Girona, E- 17003 Girona, Spain. E-mail address: nuria.perujo.buxeda@gmail.com (N. Perujo).
} 
Multiple stressors

Environmental impact assessment

DPSIR

Environmental degradation wide range of ecosystem conditions and stressors. Incorporating these guidelines may favor the comparability of scientific results and may lead to a substantial advancement in the efficacy of diagnosis and predictive approaches of impacts.

\section{Introduction}

Freshwater ecosystems have intrinsic ecological, social and economic value, but their global biodiversity declines faster than that of any other ecosystem (WWF, 2018; He et al., 2019). This decline is partly caused by the many human pressures and their associated stressors, which still are not effectively regulated in all their complex facets (Hering et al., 2015; Acuña et al., 2015). One of the reasons reducing effectiveness of environmental policies is their limited ecological basis. In many instances, the stressor magnitude, as well as its temporal (i.e. timing, duration, frequency, time between stressor events) and spatial components (e.g. Segner et al., 2014; Sabater et al., 2019; Karaouzas et al., 2018; Romero et al., 2019) are seldomly considered for the prediction of effects. Moreover, many environmental policies do not consider background stressor levels. As an example, environmental policies regulating the maximum allowed concentration of pollutants (i.e. environmental quality standards in the European Union) do not account for the co-occurrence of other non-chemical stressors (Jackson et al., 2016). There is also lot of uncertainty associated with the selection of the biological response variables to quantify impacts on freshwater ecosystems (Côté et al., 2016). The complexity and context-dependency of stressor-impact relationships (Tockner et al., 2010; Jackson et al., 2016; Segurado et al., 2018) challenges generalization among scientific studies (Orr et al., 2020), thus limiting the transferability of results into effective environmental policies. It is then necessary to properly frame stressor-impact interactions (i.e. consider key aspects that dictate stressor effects), so their outputs can be comparable, general ecological patterns can be identified, and then results can be transposed into "proactive" environmental policies.

Given this background, several frameworks have already been developed and implemented dealing with the interaction between stressors and impacts. Nevertheless, these frameworks lack some key components to understand and frame the stressor-impact relationship from a general point of view. The most commonly used frameworks are the DPSIR (i.e., Driver-Pressure-State-Impact-Response) adaptive management framework (EEA, 1999), and the ERA (Environmental Risk Assessment (EPA, 1992, EFSA, 2013)). The DPSIR is a systematic approach to environmental management in which Drivers are the socioeconomic activities (e.g., agriculture, population growth, urbanization), or climate change phenomena (e.g., global warming, rainfall distribution change) determining the occurrence of anthropogenic Pressures (e.g., diffuse pollution), which in turn modify the ecosystem's State (i.e. its physical, chemical, and biological characteristics). State changes may result in Impacts on biological receptors, triggering societal Responses to mitigate these effects (Song and Frostell, 2012). Although the DPSIR framework has been used in many studies (20,100 entries in Google Scholar, August 6th, 2020), there are still important gaps that result in a fuzzy implementation due to unclear stressorimpact relationships. For instance, the DPSIR fails to explicitly consider the term stressor (Hering et al., 2015; Birk, 2019), thus hindering its characterization (i.e. magnitude, and spatial and temporal scales). Further, the DPSIR scheme does not consider background levels of the ecosystem.

The ERA framework (4.380.000 entries in Google Scholar, August 6th 2020) has been used to predict the effect of chemical stressors on biological communities. The ERA is based on a problem formulation stage, followed by exposure and effects assessment stages, and finally the risk characterization. Recently, the term environmental scenario has been coined within the ERA. An environmental scenario consists of an exposure scenario which includes the stressor characteristics (e.g. dose, frequency, time interval) and an ecological scenario that contains the biological receptor characteristics (e.g. species and traits composition), as well as the environmental variables interacting with the biological receptor, and the spatio-temporal resolution of the assessment (Rico et al., 2016). Following this scheme, Van den Brink et al. (2019) developed a framework on a given ecosystem and spatiotemporal scale, identifying stressor intensities, the biological receptors, as well as stressor-impact relationships. Though powerful in connecting stressors and impacts, the ERA framework remains limited to a chemical perspective.

Overall, these two frameworks have led to a better characterization of the stressor-impact relationships in freshwater ecosystems, but the framing of these relationships with adequate ecological detail remains a challenge. In this overview, we zoom into these relationships, assemble and identify key characteristics of stressors and ecosystems affecting these interactions, and outline a guideline to consider them in full when assessing stressor effects. We then aim to bring new elements that can be integrated into, among others, DPSIR or ERA frameworks. This guideline should help upcoming studies to perform realistic assessments of stressor-impact relationships through proper characterization of stressor-impact relationships. This will improve the comparability of studies, and support the crucial step from correlational to predictive approaches and in turn the definition of environmentally robust policies (e.g., water quality standards). Additionally, our guideline provides a step towards ecological models to reliably predict stressor effects.

\section{General characteristics of the stressor - impact relationship}

The term stressor, here understood as any measurable change in an environmental variable caused by an anthropogenic pressure (Sabater et al., 2019), can be classified as chemical (e.g. phosphate or pesticides), physical (e.g. temperature or longitudinal connectivity) or biological (e.g. invasive species). Beyond this classification, we distinguish between stressors defined by environmental variables already present in the ecosystem previous to the pressure action (e.g. temperature, phosphate, etc.) and stressors consisting of environmental variables that are "new" to the ecosystem and which appear due to the pressure action (e.g. pesticides, industrial products, invasive species, etc.).

On one hand, magnitude in stressors defined by "new" environmental variables should account for their concentration/abundance after the pressure action (Odum et al., 1979). If the stressor is a toxicant, its chemical features (e.g. $\mathrm{K}_{\mathrm{ow}}$ ) and ecotoxicological mode of action needs to be considered (Van den Brink et al., 2019). For biological stressors, biological traits (such as feeding rate, or diet type of the invasive species) provide information of their effects and thus need to be considered (Rico et al., 2016). On the other hand, for stressors defined by environmental variables already present in the ecosystem, magnitude should be calculated as a function of the level of environmental variable in the unstressed situation, hereafter named stressor state-point. The stressor state-point changes according to the timing of the stressor, and depending on its value a given stressor magnitude may or may not cause detrimental effects on the biological response variable. As an example, Weidman et al. (2014) defined that a temperature increase at a stressor state-point of $6{ }^{\circ} \mathrm{C}$ caused no effect on alpine zooplankton density while 


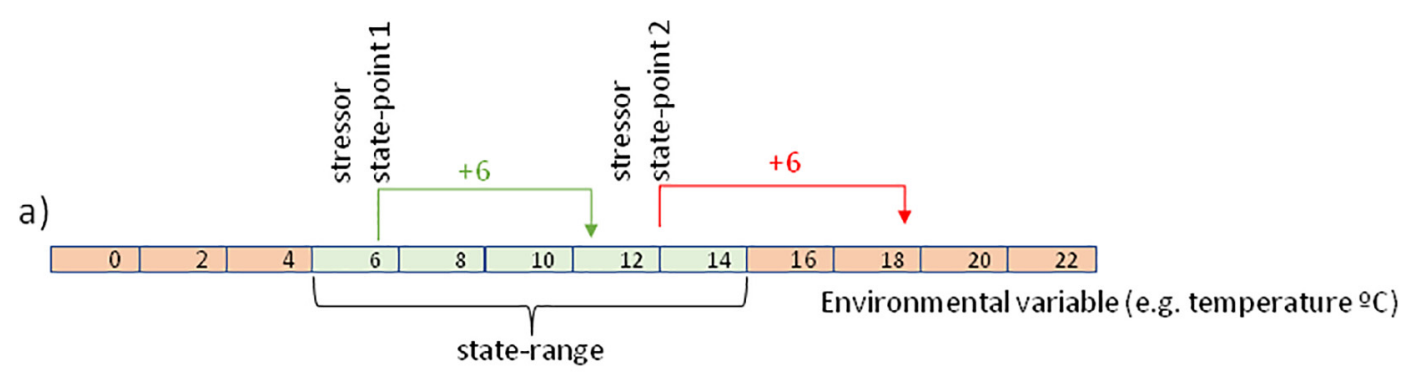

b)
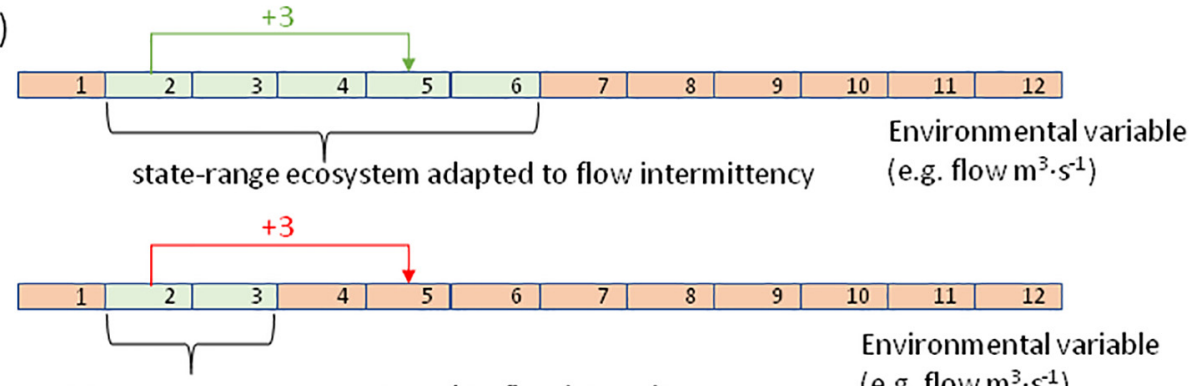

state-range ecosystem not used to flow intermittency

(e.g. flow $\mathrm{m}^{3} \cdot \mathrm{s}^{-1}$ )

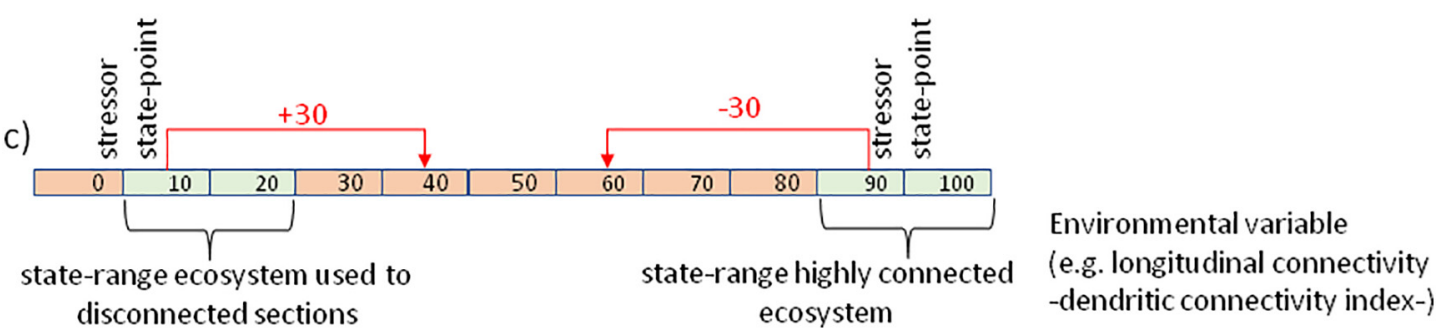

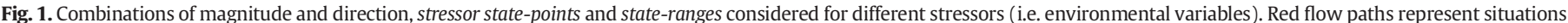

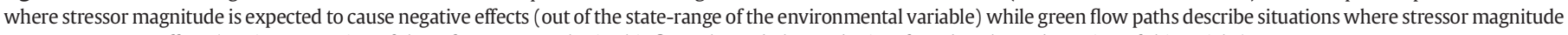
may not cause an effect. (For interpretation of the references to color in this figure legend, the reader is referred to the web version of this article.)

it caused a detrimental effect at a stressor state-point of $13^{\circ} \mathrm{C}$, suggesting that in the second case the ecosystem was pushed beyond its staterange (Fig. 1a). The state-range is not an absolute value but the natural variability of the stressor to which the ecosystem is adapted (e.g. natural annual range of temperature in the river before the stressor occurrence). The state-range is the most important feature behind the ecological thresholds and stressors' tolerance, since only if the stressor magnitude falls within the ecosystem staterange this might be resilient to changes on the biological response variable (Groffman et al., 2006). Importantly, both the stressor state-point and state-range may differ among ecosystems. In this line, ecosystems with a tight state-range (e.g. not being adapted to large hydrological variability, or used to a narrow range of nutrient concentrations) might show greater effects than ecosystems with wider state-ranges (Karaouzas et al., 2018; Perujo et al., 2016) (Fig. 1b).

The stressor magnitude can be either an increase or a decrease of the stressor variable with respect to the stressor state-point (Fig. 1c). For instance, a decrease in longitudinal connectivity calculated with the dendritic connectivity index (Cote et al., 2009)- in highly connected ecosystems (i.e. high state-range and stressor state-point values) could lead to significant changes in the biological response variable (e.g. local extinction of migratory fish species; Limburg and Waldman, 2009). At the same time, an increase in longitudinal connectivity in ecosystems used to disconnected sections (i.e. low state-range and stressor state-point values) could lead to significative changes in the biological response variable (e.g. through local species extinction due to strong interspecific interactions; Fausch et al., 2009). For stressors defined by "new" environmental variables (e.g. pollutants) organisms and ecosystems have not yet evolved adaptive strategies so there is neither state-point nor state-range.

Impact is defined as the quantifiable change produced by the stressor in a biological response variable (Orr et al., 2020). The magnitude of the impact must be calculated as function of the value of the biological response variable expected in an unstressed situation, hereafter named impact state-point (e.g. macroinvertebrate species richness upstream of a wastewater discharge point) and it can imply a decrease (i.e. detrimental effect) or an increase (i.e. beneficial effect) of the biological response variable, following the intermediate disturbance (i.e. low richness at the lowest and highest magnitude of the stressor and high richness at intermediate levels because both rapid colonizers and more competitive species cooccur Townsend et al., 1997) or the subsidy-stress hypotheses (i.e. ecosystem function depression at high magnitudes of the stressor and ecosystem function enhancement at low to medium magnitudes; Odum et al., 1979).

\section{Temporal and spatial aspects to consider}

The temporal components of stressors (i.e. duration, frequency, timing, and time elapsed between stressor events) may influence the effects produced (Segner et al., 2014; Sabater et al., 2019). Stressor effects might differ if the lapse between stressor events differs from the recovery time of the considered biological response variable (Turner et al., 1993). A recent meta-analysis detected larger negative effects under higher stressor magnitude and longer duration (Magris and Ban, 2019). Similarly, lethality of 
aquatic arthropods exposed to the insecticide diazinon was increased at longer exposure durations (Brock et al., 2008). Even though recurrent stressor events may lead to adaptive responses even to pollutants - (Brock et al., 2008), they may affect the most sensitive species and induce species loss (Gérard and Lance, 2019). The timing of the stressor occurrence is also relevant, since the ecosystem is dynamic on its physicochemical and biological variables, a clear case being the seasonal variation of environmental variables. Stressors might have a dramatically different effect depending on the season, if this coincides with the growth period of the biota (Tockner et al., 2010).

Location of the stressor in the river network might determine the spatial extent of the stressor and the spatial extent of the impact. As an example, heat pollution occurring in a headwater river segment might mainly have a local effect, but in a river segment near the river mouth might have consequences for the whole river network by impeding upstream migration of anadromous fish species (Li et al., 1994). Depending on the location of the stressor, any remaining biological reservoirs (i.e. source populations in tributaries) may or may not allow for recolonization of affected areas. For this reason, the relevant spatial scales assessing stressor effects widely differ between studies (Mantyka-Pringle et al., 2014).

Stressors do not necessarily show constant magnitude; their magnitude may change over time and space. Pesticides, for example, manifest as peak concentration to rivers (Spycher et al., 2018). Some stressors show almost constant magnitude along a river segment (e.g., laminar flux in a channelized river segment), and others show substantial spatial variations in magnitude (e.g., decreased concentration of contaminants downstream of a point pollution source) (Aristi et al., 2015). In the following example (Fig. 2), we characterize the stressor-impact relationship by the magnitude of the stressor (i.e. the change in the concentration of phosphate over space and time with respect to the stressor state-point), its temporal and spatial components and by the magnitude of the impact (i.e. the change in species richness over space and time with respect to the impact state-point).

Importantly, several stressors might co-occur (Jackson et al., 2016) leading to other effects (i.e. synergistic or antagonistic interactions) than the ones we would expect from single stressors (Crain et al., 2008). Even though species are evolutionary adapted to some extent to natural stressors (e.g. change in flow due to spring floods or the presence of pathogens), these in combination with anthropogenic stressors can cause disastrous consequences. For instance, fish populations are often no longer able to balance the impact of pathogens if they have been previously affected by pollutants. Stressors may also occur not simultaneously but sequentially, thus modifying the tolerance to stressors depending on the order of stressor occurrence. The first stressor (e.g. increase in temperature) may change species composition thereby influencing the tolerance to the second stressor (e.g. pollutants) (Janssens et al., 2017).

\section{Biological aspects to consider}

The choice of the biological response variable to assess the impact is of paramount importance. Both structural and functional variables are used as impact indicators. Functional variables (i.e. nutrient cycling, metabolism, pollutant uptake, etc.) are the first to be affected, whereas structural variables (i.e. community composition and biomass) might need longer to respond (Fig. 3a).

Biological response variables may reflect different levels of biological organization (i.e. organism-level, community-level, population-level or ecosystem-level) (Crain et al., 2008). At a community-level those organisms with short generation times such as bacteria and diatoms may respond faster (from seconds to hours) (Karaouzas et al., 2018; Segurado et al., 2018) than others with longer generation times such as macroinvertebrates, macrophytes or vertebrates (from days to years), exposed to analogous stressor characteristics (Fig. 3a). Stressor effects are progressively observed at organisms of longer than shorter life cycles;

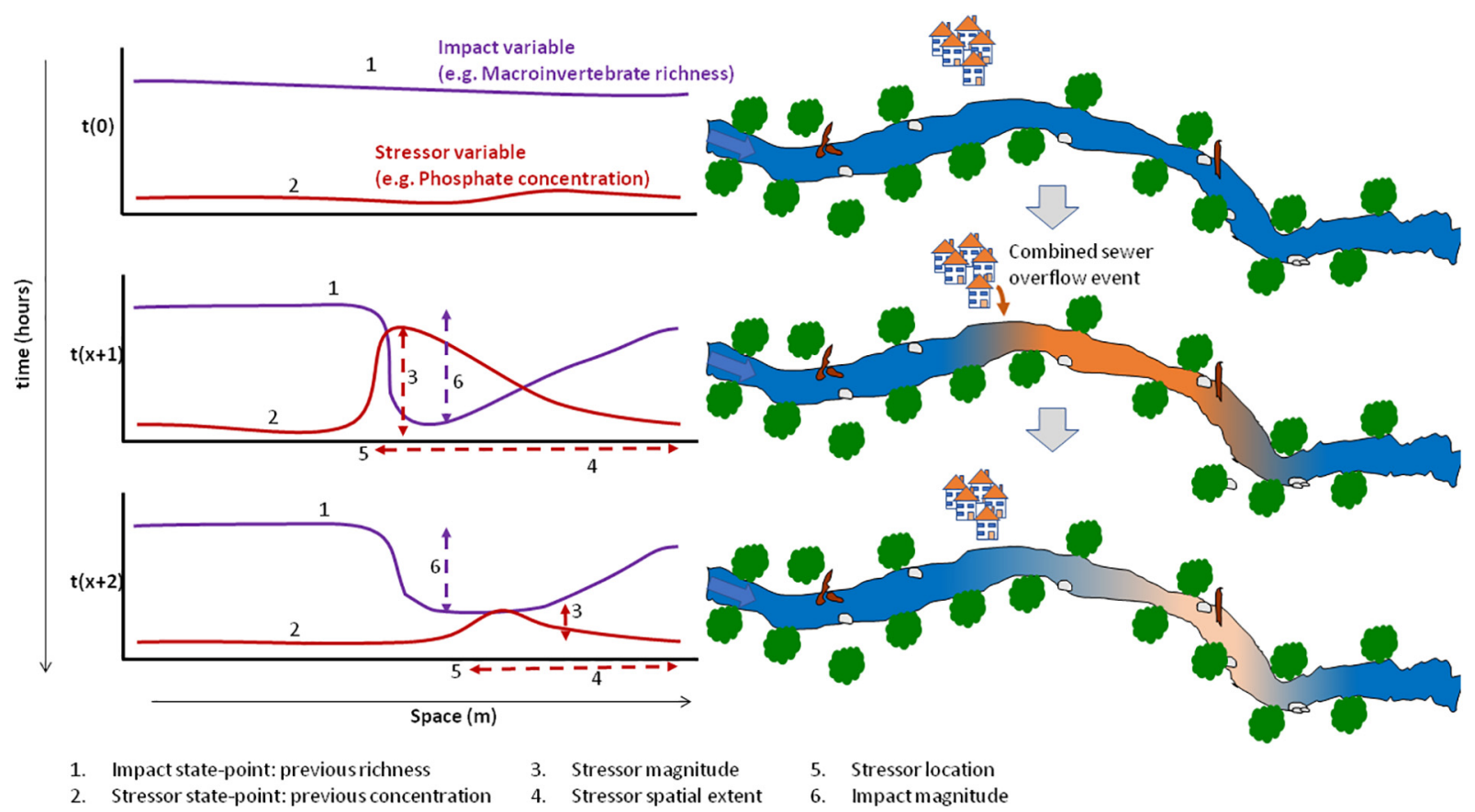

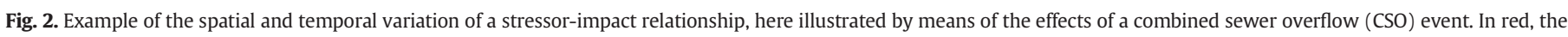

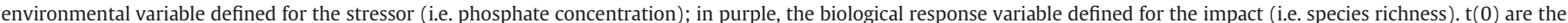

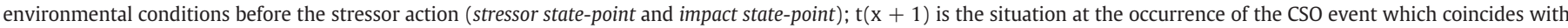

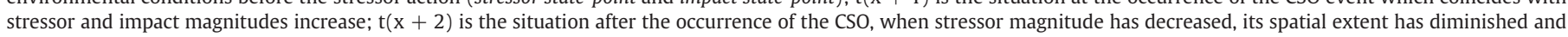
species richness has partly recovered. (For interpretation of the references to color in this figure legend, the reader is referred to the web version of this article.) 

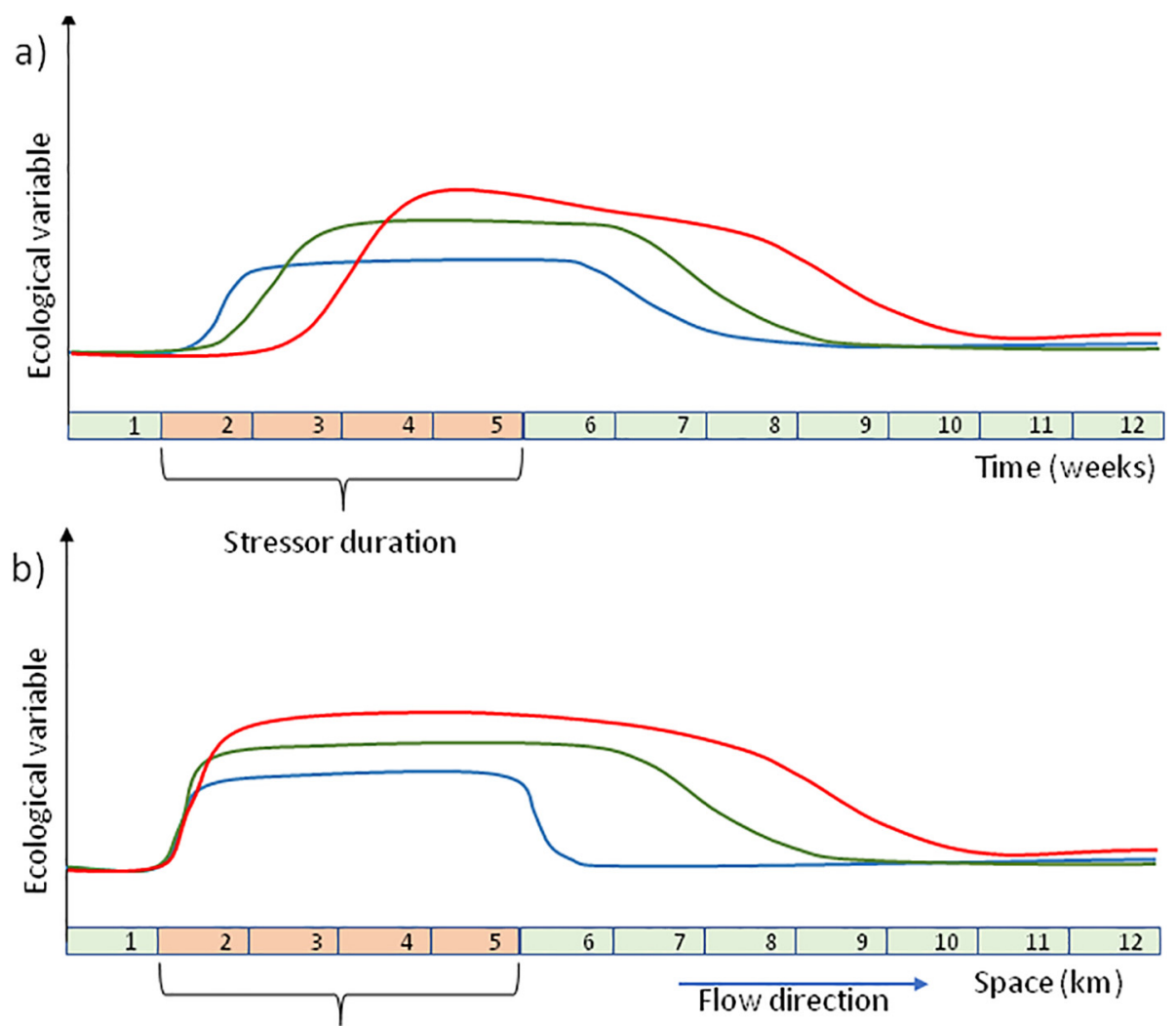

Stressor extent

Functional variable (ecosystem respiration)

Structural variable (bacterial community composition)

Structural variable (invertebrate community composition)

Fig. 3. Diagram showing differences in temporal (a) and spatial scales (b) among biological response variables.

and specifically, stronger effects have been reported for embryonic than for larval life-stages (Przeslawski et al., 2015). Although these evidences highlight the need to account for the time scale of the biological response variable considered, a recent review reported that the average experiment duration was 27 days regardless of the receptor organisms (i.e. benthic invertebrates, phytobenthos, bacteria, fungi and fishes) (Birk, 2019). The reproductive strategy of the considered organism is also an important trait, as greater toxic effects have been reported for semelpar species compared to iteropar species (Spromberg and Birge, 2005). Some organisms are able to detect the stressor and escape towards less polluted areas (e.g., Araújo et al., 2016), which favours the organism survival at a regional scale but an ecological death at the local scale. Spatial avoidance occurs when the spatial extent of the stressor is larger than the home-range of the organism, and the considered organism can actively (by swimming, flying, etc.) or passively (i.e. drift) disperse. Moreover, the spatial extent of the stressor could differ from the spatial extent of the impact depending on the considered biological response variable (Fig. 3b), as there is a match between these spatial extents for microbial communities, but not for invertebrates or vertebrates (Dafforn et al., 2016).

Specifically, stressor effects might depend on the position of the target organism within the river food web (Carpenter et al., 1985) and on food web interactions (Bracewell et al., 2019; Bruder et al., 2019). Effects may also depend on the functional role of the organism within the ecosystem and on the degree of functional redundancy existing in each trophic level (De Laender et al., 2011). The position of the organism within the food web is essential to understand the potential effect of stressors (Odum, 1985). A stressor affecting top predators may cause different effects than the same stressor affecting basal organisms, and its transmission through top-down, or bottom-up may have specific implications (Carpenter et al., 1985; Ruhí et al., 2016; Bruder et al., 2017). On this line, it has been reported that an increase in nutrient levels distorted the control by grazers on algal biomass (O'Connor et al., 2013). In ecotoxicology studies, the application of the herbicide atrazine to a lentic system resulted in lower periphyton abundance and, as a consequence, reduced herbivore biomass (Rohr and Crumrine, 2005). Relyea and Diecks (2008) showed that the application of an insecticide did not directly cause the observed death of amphibians but caused a decline in zooplankton which initiated a trophic cascade that ultimately led to the amphibian's death. Stressor effects may be less important in ecosystems having high functional redundancy, since not all species performing that function may be similarly affected. Martínez et al. (2020) observed that the increase of fine sediments affected microbial community composition but not its decomposer activity, likely due to high functional redundancy of microbial assemblages. Stressors affecting keystone species can exert an impact disproportionately large relative to their abundance (Power et al., 1996). For instance, beavers act as "ecosystem engineers" of freshwater ecosystems by modifying channel geomorphology and hydrology, and thus contribute to important ecosystem functions such as retention of sediments and organic matter (Naiman et al., 1986). Stressors affecting beavers would cause not only direct top-down effects but also indirect effects to the whole aquatic ecosystem due to habitat modification. 


\section{Conclusions and implications}

Considering the features described in the guideline in future modeling studies, in meta-analysis, as well as in decision-making frameworks such as DPSIR or ERA will provide a key breakthrough in the prediction and management of stressors in aquatic ecosystems. Our guideline provides the level of detail in stressor-impact relationship needed to delve into this relationship. It is based on detailed description of key characteristics when relating pressures to impacts. These key characteristics include the type of stressor, the state-point and state-range as well as the temporal and spatial components of the stressor. To include all these characteristics in the DPSIR framework we propose to modify it to a DPSSIR framework (Driver-Pressure-State-Stressor-Impact-Response) which specifically adds the stressor component to the framework. Environmental scenarios in ERA frameworks - mainly focused on the entities to be protected (i.e. focal taxa) and more familiarized with "impacts" than "stressors" - should be complemented by the inclusion of the stressor key characteristics described in our guideline.

Management actions aiming at improving freshwater ecosystem status greatly rely on the accurate framing of stressor effects. The consideration of our guideline in future studies of stressor effects on ecosystems will increase the accuracy of assessments of stressor effects, thus allowing inter-comparison of results, providing better predictability of stressor-impact relationships, and consequently reducing the existing uncertainty around stressor effects on our endangered freshwater ecosystems. Lack of consideration of these characteristics may lead to erroneous and confounding predictions of stressor effects and to ineffective ecosystem conservation and management.

\section{CRediT authorship contribution statement}

N. Perujo: Conceptualization, Writing - original draft, Writing review \& editing. P.J. Van den Brink: Conceptualization, Writing review \& editing. H. Segner: Conceptualization, Writing - review \& editing. C. Mantyka-Pringle: Conceptualization, Writing -review and editing. S. Sabater: Writing - review \& editing. S. Birk: Conceptualization. A. Bruder: Conceptualization. F. Romero: Writing - review \& editing. V. Acuña: Conceptualization, Writing - original draft, Writing - review \& editing.

\section{Declaration of competing interest}

The authors declare that they have no known competing financial interests or personal relationships that could have appeared to influence the work reported in this paper.

\section{Acknowledgements}

This research was funded by the projects SPACESTREAM (CGL201788640-C2-1-R) and CLIMALERT (PCIN-2017- 068) of the Ministry of Economy and Competitiveness, the Catalan Water Agency (ACA) by the project EESAM (ACA210/18/00028), and the Economy and Knowledge Department of the Catalan Government through the Consolidated Research Group (ICRAENV2017 SGR 1124). ICRA researchers acknowledge funding from the CERCA program.

\section{Appendix A}

Appendix A: 3-step guideline. Includes: Panel A.1 First step of the guideline to frame stressor effects based on identifying stressor characteristics according to the stressor type (i.e. defined by environmental variables already existing or by "new" environmental variables); Panel A.2 Second step of the guideline to frame stressor effects based on identifying temporal and spatial components of the stressor as well as the co-occurrence of other stressors; Panel A.3 Third step of the guideline to frame stressor effects based on characterization of the biological response variable that is used as an impact indicator as well as defining characteristics linked to potential food web interactions.

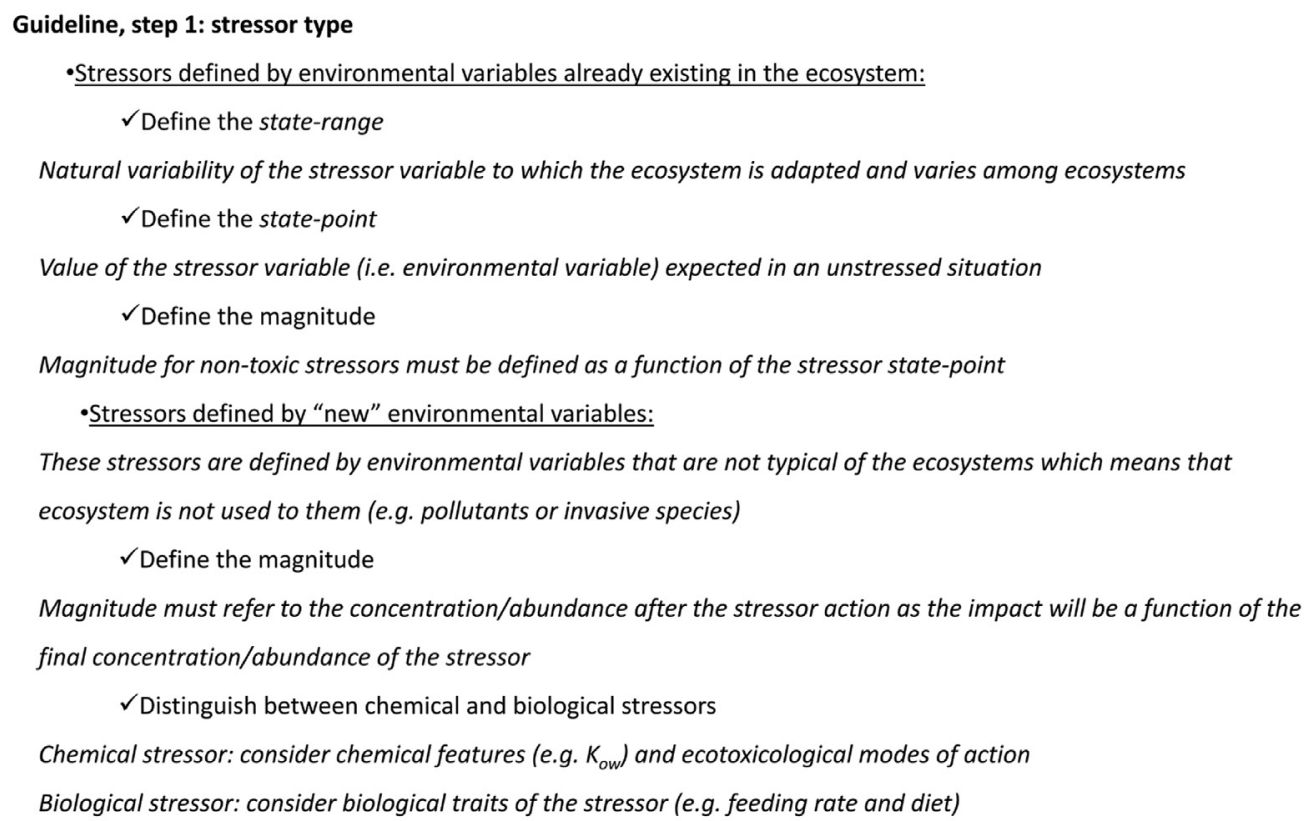

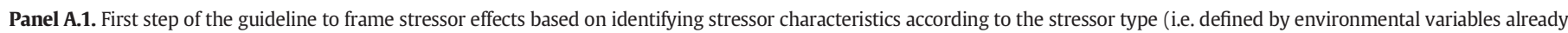
existing or by "new" environmental variables). 


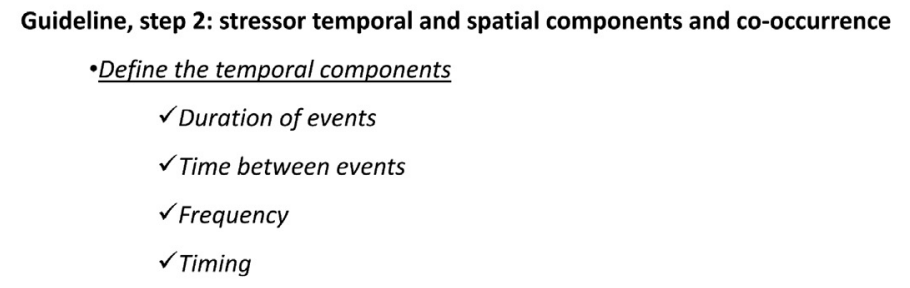

Refers to environmental characteristics (others than stressor variable) at the time when the stressor action occurs.

These environmental variables - which in turn are affected by seasonal variation-, interact with the stressor variable and/or with the biological response variable

$\checkmark$ Temporal variation of stressor magnitude

- Define the spatial components

$\checkmark$ Stressor location and stressor spatial extent

$\checkmark$ Spatial variation of stressor magnitude

- Co-occurrence of other stressors

$\checkmark$ Identify the presence of other stressors

Other stressors (including natural stressors such as pathogens) might co-occur with the considered stressor leading to

not additive effects (i.e. synergistic or antagonistic interactions)

$\checkmark$ Identify the sequential order of other stressors

Stressors may occur not simultaneously but sequentially

Panel A.2. Second step of the guideline to frame stressor effects based on identifying temporal and spatial components of the stressor as well as the co-occurrence of other stressors.

\author{
Guideline, step 3: impact \\ The term impact refers to stressor effects in a biological response variable. \\ - Choose the impact indicator (i.e. biological response variable) \\ $\checkmark$ Define the organizational level (i.e. organism-level, community-level, population-level or ecosystem-level) \\ $\checkmark$ Biological traits \\ Specific biological traits of the organism behind the biological response variable must be considered (e.g. generation \\ times, life-stage, dispersal ability, spatial avoidance, home-range size, among others) \\ -Food-web interactions \\ $\checkmark$ Position in the food web \\ $\checkmark$ Functional redundancy \\ $\checkmark$ Keystone species \\ Stressor affecting keystone species would cause not only direct effects but also indirect effects to the whole aquatic \\ ecosystem due to habitat modification
}

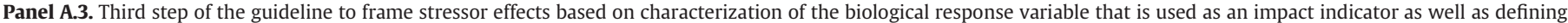
characteristics linked to potential food web interactions.

\section{References}

Acuña, V., Ginebreda, A., Mor, J.R., et al., 2015. Balancing the health benefits and environmental risks of pharmaceuticals: Diclofenac as an example. Environ. Int. 85, 327-333.

Aristi, I., von Schiller, D., Arroita, M., et al., 2015. Mixed effects of effluents from a wastewater treatment plant on river ecosystem metabolism: subsidy or stress? Freshw. Biol. 60, 1398-1410.

Araújo, C.V., Moreira-Santos, M., Ribeiro, R., 2016. Active and passive spatial avoidance by aquatic organisms from environmental stressors: a complementary perspective and a critical review. Environ. Int. 92, 405-415.

Birk, S., 2019. Detecting and quantifying the impact of multiple stress on river ecosystems. In: Sabater, S., Elosegi, A., Ludwig, R. (Eds.), Multiple Stressors in River Ecosystems: Status, Impacts and Prospects for the Future. Elsevier Inc. Amsterdam, Netherlands.

Bracewell, S., Verdonschot, R.C.M., Schäfer, R.B., et al., 2019. Qualifying the effects of single and multiple stressors on the food web structure of Dutch drainage ditches using a literature review and conceptual models. Sci. Total Environ. 684, 727-740.
Brock, T.C., Solomon, K.R., van Wijngaarden, R., Maltby, L., de Zwart, D., et al., 2008. Temporal extrapolation in ecological effect assessment of chemicals. In: Solomon, K.R., Brock, T.C.M. (Eds.), Extrapolation Practice for Ecotoxicological Effect Characterization of Chemicals. SETAC Press, New York.

Bruder, A., Salis, R.K., Jones, P.E., Matthaei, C.D., 2017. Biotic interactions modify multiplestressor effects on juvenile brown trout in an experimental stream food web. Glob. Chang. Biol. 23, 3882-3894.

Bruder, A., Frainer, A., Rota, T., Primicerio, R., 2019. The importance of ecological networks in multiple-stressor research and management. Front. Environ. Sci 7, 1-7.

Carpenter, S.R., Kitchell, J.F., Hodgson, J.R., 1985. Fish predation and herbivory can regulate lake ecosystems. Bioscience 35, 634-639.

Cote, D., Kehler, D.G., Bourne, C., Wiersma, Y.F., 2009. A new measure of longitudinal connectivity for stream networks. Landsc. Ecol. 24, 101-113.

Côté, I.M., Darling, E.S., Brown, C.J., 2016. Interactions among ecosystem stressors and their importance in conservation. Proc. R. Soc. B Biol. Sci. 283, 1-9.

Crain, C.M., Kroeker, K., Halpern, B.S., 2008. Interactive and cumulative effects of multiple human stressors in marine systems. Ecol. Lett. 11, 1304-1315. 
Dafforn, K.A., Johnston, E.L., Ferguson, A., et al., 2016. Big data opportunities and challenges for assessing multiple stressors across scales in aquatic ecosystems. Mar. Freshw. Res. 67, 393-413.

De Laender, F., Van Den Brink, P.J., Janssen, C.R., 2011. Functional redundancy and food web functioning in linuron-exposed ecosystems. Environ. Pollut. 159, 3009-3017.

EEA, 1999. Environmental Indicators: Typology and Overview. Copenhagen, Denmark.

EFSA, 2013. Guidance on tiered risk assessment for plant protection products for aquatic organisms in edge-of-field surface waters. EFSA J. 11, 3290.

EPA, 1992. Framework for Ecological Risk Assessment (Washington).

Fausch, K.D., Rieman, B.E., Dunham, J.B., et al., 2009. Invasion versus isolation: trade-offs in managing native salmonids with barriers to upstream movement. Conserv. Biol. 23 859-870.

Gérard, C., Lance, E., 2019. Decline of freshwater gastropods exposed to recurrent interacting stressors implying cyanobacterial proliferations and droughts. Aquat. Ecol. 53, 79-96.

Groffman, P.M., Baron, J.S., Blett, T., et al., 2006. Ecological thresholds: the key to successful environmental management or an important concept with no practical application? Ecosystems 9, 1-13

He, F., Zarfl, C., Bremerich, V., et al., 2019. The global decline of freshwater megafauna. Glob. Chang. Biol. 25, 3883-3892.

Hering, D., Carvalho, L., Argillier, C., et al., 2015. Managing aquatic ecosystems and water resources under multiple stress - an introduction to the MARS project. Sci. Total Environ. 503-504, 10-21.

Jackson, M.C., Loewen, C.J.G., Vinebrooke, R.D., Chimimba, C.T., 2016. Net effects of multiple stressors in freshwater ecosystems: a meta-analysis. Glob. Chang. Biol. 22, 180-189.

Janssens, L., Tüzün, N., Stoks, R., 2017. Testing the time-scale dependence of delayed interactions: a heat wave during the egg stage shapes how a pesticide interacts with a successive heat wave in the larval stage. Environ. Pollut. 230, 351-359.

Karaouzas, I., Smeti, E., Vourka, A., et al., 2018. Assessing the ecological effects of water stress and pollution in a temporary river - implications for water management. Sci. Total Environ. 618, 1591-1604.

Li, H.W., Lamberti, G.A., Pearsons, T.N., et al., 1994. Cumulative effects of riparian disturbances along high desert trout streams of the john day basin, Oregon. Trans. Am. Fish. Soc. 123, 627-640.

Limburg, K.E., Waldman, J.R., 2009. Dramatic declines in North Atlantic Diadromous fishes. Bioscience 59, 955-965.

Magris, R.A., Ban, N.C., 2019. A meta-analysis reveals global patterns of sediment effects on marine biodiversity. Glob. Ecol. Biogeogr. 28, 1879-1898.

Mantyka-Pringle, C.S., Martin, T.G., Moffatt, D.B., et al., 2014. Understanding and predicting the combined effects of climate change and land-use change on freshwater macroinvertebrates and fish. J. Appl. Ecol. 51, 572-581.

Martínez, A., Lírio, A.V., Febra, I., et al., 2020. Functional redundancy in leaf-litterassociated aquatic hyphomycetes: fine sediment alters community composition but hardly decomposer activity. Int. Rev. Hydrobiol. 105, 44-51.

Naiman, R.J., Melillo, J.M., Hobbie, J.E., 1986. Ecosystem alteration of boreal forest streams by beaver (Castor Canadensis). Ecology 67, 1254-1269.

O'Connor, N.E., Emmerson, M., Crowe, T.P., Donohue, I., 2013. Distinguishing between direct and indirect effects of predators in complex systems. J. Anim. Ecol. 82, 438-448.

Odum, E.P., 1985. Trends expected in stressed ecosystems. Bioscience 35, 419-422.

Odum, E.P., Finn, J.T., Franz, E.H., 1979. Perturbation theory and the subsidy-stress gradient. Bioscience 29, 349-352.
Orr, J.A., Vinebrooke, R.D., Jackson, M.C., et al., 2020. Towards a unified study of multiple stressors: divisions and common goals across research disciplines. Proc. R. Soc. B Biol. Sci. 287, 1-10

Perujo, N., Freixa, A., Vivas, Z., et al., 2016. Fluvial biofilms from upper and lower river reaches respond differently to wastewater treatment plant inputs. Hydrobiologia $765,169-183$.

Power, M.E., Tilman, D., Estes, J.A., et al., 1996. Challenges in the quest for keystones. Bioscience 46, 609-620.

Przeslawski, R., Byrne, M., Mellin, C., 2015. A review and meta-analysis of the effects of multiple abiotic stressors on marine embryos and larvae. Glob. Chang. Biol. 21, 2122-2140.

Relyea, R.A., Diecks, N., 2008. An unforeseen chain of events: lethal effects of pesticides on frogs at sublethal concentrations. Ecol. Appl. 18, 1728-1742.

Rico, A., Van den Brink, P.J., Gylstra, R., et al., 2016. Developing ecological scenarios for the prospective aquatic risk assessment of pesticides. Integr. Environ. Assess. Manag. 12, $510-521$.

Rohr, J.R., Crumrine, P.W., 2005. Effects of an herbicide and an insecticide on pond community structure and processes. Ecol. Appl. 15, 1135-1147.

Ruhí, A., Acuña, V., Barceló, D., et al., 2016. Bioaccumulation and trophic magnification of pharmaceuticals and endocrine disruptors in a Mediterranean river food web. Sci. Total Environ. 540, 250-259.

Romero, F., Acuña, V., Font, C., Freixa, A., Sabater, S., 2019. Effects of multiple stressors on river biofilms depend on the time scale. Sci. Rep. 9 (1), 1-12

Sabater, S., Elosegi, A., Ludwig, R., 2019. Defining multiple stressor implications. In: Sabater, S., Elosegi, A., Ludwig, R. (Eds.), Multiple Stressors in River Ecosystems: Status, Impacts and Prospects for the Future. Elsevier Inc., Amsterdam, Netherlands.

Segner, H., Schmitt-Jansen, M., Sabater, S., 2014. Assessing the impact of multiple stressors on aquatic biota: the receptor's side matters. Environ. Sci. Technol. 48, 7690-7696.

Segurado, P., Almeida, C., Neves, R., et al., 2018. Understanding multiple stressors in Mediterranean basin: combined effects of land use, water scarcity and nutrient enrichment. Sci. Total Environ. 624, 1221-1233.

Song, X., Frostell, B., 2012. The DPSIR framework and a pressure-oriented water quality monitoring approach to ecological river restoration. Water (Switzerland) 4, 670-682

Spromberg, J.A., Birge, W.J., 2005. Modeling the effects of chronic toxicity on fish populations: the influence of life-history strategies. Environ. Toxicol. Chem. 24, 1532-1540.

Spycher, S. Mangold, S. Doppler, T. et al. 2018. Pesticide risks in small streams - how to get as close as possible to the stress imposed on aquatic organisms. Environ. Sci. Technol. 52, 4526-4535.

Tockner, K., Pusch, M., Borchardt, D., Lorang, M.S., 2010. Multiple stressors in coupled river-floodplain ecosystems. Freshw. Biol. 55, 135-151.

Townsend, C.R., Scarsbrook, M.R., Dolédec, S., 1997. The intermediate disturbance hypothesis, refugia, and biodiversity in streams. Limnol. Oceanogr. 42, 938-949.

Turner, M.G., Romme, W.H., Gardner, R.H., et al., 1993. A revised concept of landscape equilibrium: disturbance and stability on scaled landscapes. Landsc. Ecol. 8, 213-227.

Van den Brink, P.J., Bracewell, S.A., Bush, A., et al., 2019. Towards a general framework for the assessment of interactive effects of multiple stressors on aquatic ecosystems: results from the making aquatic ecosystems great again (MAEGA) workshop. Sci. Total Environ. 684, 722-726.

Weidman, P.R., Schindler, D.W., Thompson, P.L., Vinebrooke, R.D., 2014. Interactive effects of higher temperature and dissolved organic carbon on planktonic communities in fishless mountain lakes. Freshw. Biol. 59, 889-904.

WWF, 2018. In: Grooten, M., Almond, R.E.A. (Eds.), Living Planet Report 2018: Aiming Higher. 